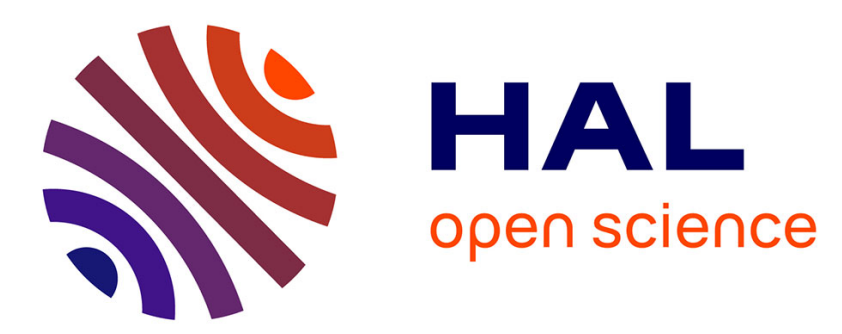

\title{
First principles account for large changes in electronic structure and bonding from $\mathrm{LaCu}$ to $\mathrm{LaCuMg}$ and $\mathrm{LaCuMg} 4$
}

\author{
Samir F. Matar, Adel F. Al Alam, Naim N. Ouaini
}

\section{To cite this version:}

Samir F. Matar, Adel F. Al Alam, Naim N. Ouaini. First principles account for large changes in electronic structure and bonding from $\mathrm{LaCu}$ to $\mathrm{LaCuMg}$ and $\mathrm{LaCuMg} 4$. Computational Materials Science, 2015, 97, pp.231-236. 10.1016/j.commatsci.2014.10.016 . hal-01100665

\section{HAL Id: hal-01100665 \\ https://hal.science/hal-01100665}

Submitted on 6 Jan 2015

HAL is a multi-disciplinary open access archive for the deposit and dissemination of scientific research documents, whether they are published or not. The documents may come from teaching and research institutions in France or abroad, or from public or private research centers.
L'archive ouverte pluridisciplinaire HAL, est destinée au dépôt et à la diffusion de documents scientifiques de niveau recherche, publiés ou non, émanant des établissements d'enseignement et de recherche français ou étrangers, des laboratoires publics ou privés. 
Computational Materials Science, Elsevier. Accepted Oct 2014.

First principles account for large changes in electronic structure and bonding from $\mathrm{LaCu}$ to $\mathrm{LaCuMg}$ and $\mathrm{LaCuMg}_{4}$

\author{
S.F. Matar ${ }^{1,2^{*}}$, A.F. Al Alam ${ }^{3,4}$, N. Ouaini ${ }^{3}$. \\ ${ }^{1}$ CNRS, ICMCB, UPR 9048, F-33600 Pessac, France. \\ 2 Université de Bordeaux, ICMCB, UPR 9048, F-33600 Pessac, France. \\ ${ }^{3}$ Holy Spirit University of Kaslik (USEK), CNRS- $L$, CSR-USEK, Jounieh, Lebanon. \\ ${ }^{4}$ University of Balamand, Department of Physics, P.O. Box 100, Tripoli, Lebanon.
}

*Corresponding author: matar@icmcb-bordeaux.cnrs.fr; abouliess@gmail.com

Keywords: DFT; Equation of state; cohesive energy; Chemical bonding.

\begin{abstract}
Increasing amounts of magnesium in $\mathrm{LaCu}$ intermetallic are shown to bring drastic electronic, chemical and mechanical changes. Based on DFT methodologies this is quantified for the cohesive energies, relative charge transfers, bulk modules, electronic structures and bonding properties for the three compounds $\mathrm{LaCu}, \mathrm{LaCuMg}$ and $\mathrm{LaCuMg}_{4}$. Particularly the cohesive energies increase with $\mathrm{Mg}$ amounts: This is illustrated by the increasing number of pair interactions: While in the binary the bonding is ensured by $\mathrm{La}-\mathrm{Cu}$, in the ternaries $\mathrm{La}-\mathrm{Cu}$, $\mathrm{La}-\mathrm{Mg}$ and $\mathrm{Cu}-\mathrm{Mg}$ interactions contribute to the bonding with the extra electrons brought by $\mathrm{Mg}$ occupying bonding states. Along the series, increasing magnesium contents lead to moderate increase of the compressibility.
\end{abstract}

\title{
Introduction
}

Magnesium rich compounds are of interest in the field of materials science for crystal chemistry fundamentals [1,2] and for different applications like corrosion resistance compounds such as within the Mg-Zn-RE ternary system (RE: Rare Earth) [3] as well as host compounds for hydrogen storage in the solid state [4,5]. In the $\mathrm{La}-\mathrm{Cu}-\mathrm{Mg}$ phase diagram [6] the $\mathrm{Mg}$ rich ternary compound $\mathrm{LaCuMg}_{4}$ (1:1:4) was discovered and structurally determined from ab initio in the hexagonal $\mathrm{UCoAl}_{4}$-type structure with $P \overline{6} m 2$ space group, cf. [7] for a 
detailed description. The structure consists of $\mathrm{LaCuMg}$ planes interlayered by magnesium planes formed by three $\mathrm{Mg}$ (Fig. 1a). Mg-Mg distances are in the range of $\sim 3 \AA$. This is close to the sum of $\mathrm{Mg}$ metallic radii, and metallic-like $\mathrm{Mg}$ networks can be expected. Note that short $\mathrm{Mg}-\mathrm{Mg}$ connections are found in other ternary magnesium rich compounds as $\mathrm{CeRu}_{2} \mathrm{Mg}_{5}$ and $\mathrm{Ce}_{2} \mathrm{Ru}_{4} \mathrm{Mg}_{17}$ [8]. The 1:1:4 structure presents similarities with equiatomic $\mathrm{LaCuMg}(1: 1: 1)$ which also crystallizes in the $P \overline{6} \mathrm{~m} 2$ space group while adopting the ZrNiAltype structure [7]. The additional $\mathrm{Mg}$ substructures lead to an almost doubling of the cell volume from 1:1:1 to 1:1:4. Another difference between the two structures is found in the two copper sites $\mathrm{Cu} 1$ and $\mathrm{Cu} 2$ (Table 1): whereas they occupy the same plane in $\mathrm{LaCuMg}_{4}$, they are found at $z=0$ and $z=1 / 2$ in $\mathrm{LaCuMg}$. As a consequence the structure consists of $\mathrm{LaCul}$ planes interlayered by $C u 2 M g$ along the hexagonal $c$ axis (Fig. 1b). These structural modifications are likely to induce changes in the electronic structure and the bonding behaviors. They can be approached complementarily to crystal lattice determination with quantum theoretical methods to obtain the energies (total and cohesive) and the energyvolume equations of states (EOS) as well as the overlap populations $\left(\mathrm{S}_{\mathrm{ij}}\right)$ analysis to describe the chemical bonding and the trends of charge transfers. Consequently the purpose of the paper is to provide an accurate account of the role played by increasing amounts of $\mathrm{Mg}$ along the series $\mathrm{LaCu}, \mathrm{LaCuMg}$ and $\mathrm{LaCuMg}_{4}$ with computational methods within the well established framework of the quantum density functional theory (DFT) $[9,10]$.

\section{Computational framework}

Two methods were used complementarily. Firstly total-energy and force calculations were performed using the VASP package $[11,12]$ for optimizing the structures and establishing trends of charge transfers and the energy volume equations of states (EOS). The projectoraugmented wave (PAW) method was used to solve the single-particle equations [12, 13]. Exchange and correlation effects were accounted for within the GGA following Perdew, Burke and Ernzerhof [14]. The optimization of the structural parameters was performed until the Hellmann-Feynman forces acting on the atoms were less than $10^{-2} \mathrm{eV} . \AA^{-1}$ and stress components less than $10^{-3} \mathrm{eV} . \AA^{-3}$. The expansion of the Kohn-Sham orbitals was operated with a plane wave energy cutoff of $400 \mathrm{eV}$. The Brillouin-zone (BZ) integrals were approximated with a special precise $k$-point sampling following Monkhorst and Pack [15]: For the hexagonal structures of the ternary title compounds, this implies grid sizes of $24 \times 24$ $\times 8$ and $24 \times 24 \times 24$ for the orthorhombic structure of $\mathrm{LaCu}$. 
The charge density resulting from the calculations was analyzed with the theory of atoms in molecules (AIM) [16] as based purely on the electronic charge density. The so-called Bader analysis is particularly useful when trends between similar compounds need to be examined; consequently such a tool cannot allow evaluating absolute ionizations.

Secondly, for an account of the electronic structure and particularly of the properties of chemical bonding not available with VASP, the scalar relativistic full-potential augmented spherical wave (ASW) method was used [17-19]. Like above the DFT exchange and correlation effects were accounted for within the GGA treated with a different parameterization scheme [20]. For the valence states the ASW method uses the outermost shells to represent a minimal basis set with one of each kind, i.e. $s, p, d, f$. The matrix elements are constructed with partial waves up to $l_{\max }+1=4$ for $\mathrm{La} ; l_{\max }+1=3$ for $\mathrm{Cu}$ and $l_{\max }+1=2$ for $\mathrm{Mg} ; l$ being the secondary quantum number. Self-consistency is considered as achieved when charge transfers and energy variation between two consecutive cycles were less than $10^{-8} \times e$ and $10^{-6} \mathrm{eV}$, respectively. The $\mathrm{BZ}$ integrations are performed using the linear tetrahedron method within its irreducible wedge [21]. The pair interactions between atomic constituents are discussed based on the crystal orbital overlap population $\mathrm{S}_{\mathrm{ij}}$ with the COOP criterion [22]. Bonding, non-bonding and anti-bonding states are designated by positive, nil and negative COOP magnitudes along the $y$ axis (cf. Figs. 4 and 5).

\section{Geometry optimization, charge transfers and energy-volume EOS.}

\section{Geometry optimization and relative charge transfers.}

Starting from the experimental structure parameters of $\mathrm{LaCuMg}$ and $\mathrm{LaCuMg}_{4}[6,7]$ given in Table 1, unconstrained geometry optimization runs were carried out. Similar calculations were done for $\mathrm{LaCu}$ which crystallizes in $\mathrm{FeB}$-type orthorhombic structure (Pnma space group) [23]. In both ternary compounds the hexagonal symmetry in $P \overline{6} m 2$ space group is preserved after successive calculations with increasing precision of the BZ. As shown in Table 1, the fully relaxed structure parameters are found close to starting ones and the shortest interatomic distances are in fair agreement with experiment. Especially $\mathrm{d}(\mathrm{La}-\mathrm{Cu})$ is smallest in $\mathrm{LaCu}$ and increases in the ternaries due to the cell expansion. In $\mathrm{LaCuMg}_{4}$ the shortest metal-magnesium separations are for $\mathrm{Cu}-\mathrm{Mg} 1$ and $\mathrm{Cu}-\mathrm{Mg} 2$, and $\mathrm{Cu}-\mathrm{Mg} 3$ in $\mathrm{LaCuMg}$ structure. It is important to mention that $\mathrm{Cu} 1$ located at $(0,0,0)$ plane has the shortest separation with $\mathrm{Mg}$ in both compounds. Larger distances characterize the $\mathrm{La}-\mathrm{Mg}$ connections. 
This lets suggest different trends in charge transfers $(Q / e)$ along the different substructures. The last columns of Tables 1 present the charge transfers showing the common trend of positively charged $\mathrm{La}$ and $\mathrm{Mg}$ and negatively charged copper. This follows from the relative electronegativities of the different chemical species: $\chi(\mathrm{Cu})=1.90 ; \chi(\mathrm{Mg})=1.31$ and $\chi(\mathrm{La})=$ 1.10. The 1:1:4 ternary with highest $\mathrm{Mg}$ concentration clearly shows a reduced amount of transferred charges compared to $\mathrm{LaCuMg}$ and $\mathrm{LaCu}$. For instance, the charge carried by $\mathrm{La}$ goes down from $+0.97 e$ for $\mathrm{LaCu}$ through $+0.63 e$ for $1: 1: 1$ to $+0.58 e$ for $1: 1: 4$. Nevertheless the overall charge transfer from $\mathrm{Mg}$ is small. The lowest magnitudes are found in the 1:1:4 ternary approaching zero whereas $\mathrm{Mg}$ in 1:1:1 carries a positive charge of $0.18 e$. Such small magnitudes are significant of covalent like bonding illustrated in next section.

\section{Cohesive energies.}

The question arises as to the role of $\mathrm{Mg}$ 'adjunction/insertion' in the binary intermetallic on the relative stabilities of the ternaries versus $\mathrm{LaCu}$. This is quantified from examining the magnitudes of the cohesive energies.

$E_{\text {coh. }}=E_{\text {total }}($ compound $)-\Sigma E$ (constituents) for one FU.

The energies of the constituents were calculated in their ground state structures. $\mathrm{Mg}$ (hexagonal, with $2 p^{6}$ semi-core states): $-2.784 \mathrm{eV}$ (2 atoms); La (hexagonal): $-9.48 \mathrm{eV}$ (2 atoms) and $\mathrm{Cu}(\mathrm{FCC}):-3.715 \mathrm{eV}$ (1 atom). The resulting $E_{\text {coh. }}$ are given in Table 1 per FU. The trends of $E_{\text {coh. }}(\mathrm{LaCu})=-0.35 \mathrm{eV}$ to $E_{\text {coh. }}(\mathrm{LaCuMg})=-0.67 \mathrm{eV}$ then $E_{\text {coh. }}\left(\mathrm{LaCuMg}_{4}\right)=-$ $1.41 \mathrm{eV}$ clearly show enhanced cohesion of the structures upon insertion of $\mathrm{Mg}$ and up to the Mg saturated 1:1:4 composition.

\section{Energy-volume equations of states}

The volume expansions from $\mathrm{LaCu}$ to $\mathrm{LaCuMg}(47 \%)$ and from $\mathrm{LaCuMg}$ to $\mathrm{LaCuMg}_{4}$ (95\%) is remarkably large and should have consequences on the compressibility of the compounds, i.e. the larger the volume the more compressible the compound. However the bonding between the nearest neighbors can hinder this effect and reduce the compressibility. The prevailing effect can be obtained through the energy-volume equations of state (EOS) for the three compounds. This proceeds from the $E, V$ (energy-volume) set of calculations around the minima found from the geometry optimization (Table 1). The resulting $E=f(V)$ curves are 
shown in Figs. 2. They have a quadratic variation which can be fitted with Birch EOS up to the $3^{\text {rd }}$ order [24]:

$E(V)=E_{\mathrm{o}}\left(V_{\mathrm{o}}\right)+(9 / 8) V_{\mathrm{o}} B_{\mathrm{o}}\left[\left(\left[\left(\mathrm{V}_{\mathrm{o}}\right) / \mathrm{V}\right]\right)^{[2 / 3]} \mathrm{B}^{\prime}-1\right]^{2}+[9 / 16] \mathrm{B}_{\mathrm{o}}\left(\mathrm{B}^{\prime}-4\right) \mathrm{V}_{\mathrm{o}}\left[\left(\left[\left(\mathrm{V}_{\mathrm{o}}\right) / \mathrm{V}\right]\right)^{[2 / 3]}-1\right]^{3}$,

where $E_{\mathrm{o}}, V_{\mathrm{o}}, B_{\mathrm{o}}$ and $B^{\prime}$ are the equilibrium energy, the volume, the bulk modulus and its pressure derivative, respectively. The fit results in the inserts of Fig. 2 show close values of equilibrium energies $E_{0}$ and volumes $V_{0}$ to the ones obtained by energy optimization (Table 1). All three $B^{\prime}$ values are close to 4 , i.e. within range of usually obtained values [25]. The magnitude of $B_{0}(\mathrm{LaCu})=53 \mathrm{GPa}$ (no experimental value is available to the best of our knowledge) is within range of binary $R E \mathrm{~T}$ intermetallics ( $\mathrm{T}$ : transition metal of the $1^{\text {st }}$ period) [25]. The relevant trend is in the decrease of $B_{0}$ from $\mathrm{LaCu}(53 \mathrm{GPa})$ to $\mathrm{LaCuMg}$ (49 GPa) then to $\mathrm{LaCuMg}_{4}(44 \mathrm{GPa})$ with steps of $\Delta B_{0}=5 \mathrm{GPa}$. This follows the increase of the volume especially from $\mathrm{LaCuMg}$ to $\mathrm{LaCuMg}_{4}$ whereby the compound with the largest volume becomes most compressible under hydrostatic pressure. However the increase of compressibility is not large enough to assign the only effect to volume change and it can be proposed that the bonding between the atomic constituents is a limiting factor to large changes in compressibility.

\section{All electrons calculations and chemical bonding.}

In so far that the calculated crystal results are in fair agreement with experiment we used the latter for a full assessment of the electronic structure and the qualitative description of the chemical bonding based on the overlap populations. This allows independent comparisons between the results of the two methods in use. At self consistent convergence of the charges and of the (variational) energy, the amount and the sign of charge transfer are similar to the Bader analysis above.

\section{Site projected density of states}

The site projected densities of states (PDOS) are displayed in Fig. 3. The zero energy along the $x$ axis is taken with respect to the Fermi energy $\left(\mathrm{E}_{\mathrm{F}}\right)$. The valence band $(\mathrm{VB})$ is characterized by $\mathrm{Cu} d$ states centered at $\sim-3 \mathrm{eV}$. An inversion of the relative PDOS positions of $\mathrm{Cu} 1$ and $\mathrm{Cu} 2$ is observed between " $1: 1: 1 "$ " and " $1: 1: 4$ " compounds due to their belonging to different planes (at $z=0$ and $z=1 / 2$ ) in the former and to the same plane $(z=0)$ in the latter. Empty La $4 f$ states are found at $2 \mathrm{eV}$, well above $\mathrm{EF}_{\mathrm{F}}$ within the conduction band (CB). Then 
La is expected to contribute to the bonding with neighboring ligands mainly through the itinerant $d$ states which are of low intensity and smeared over the VB. In particular, $\operatorname{Mg}(s, p)$ states are observed below the copper DOS crossing EF (Fig. 3c). From the binary to the equiatomic ternary and the 1:1:4 compound a narrowing of the $\mathrm{Cu}$ and La PDOS can be observed. This arises from the volume increase leading to larger localization of the respective $3 d$ and $4 f$ states.

\section{Chemical bonding}

The resembling PDOS between the different species indicates the bonding between them through the quantum mixing between the valence states. Such bonding is rationalized based on the overlap matrix elements $S_{\mathrm{ij}}$ within the COOP scheme [22]. In as far as the atomic species exist with different stoichiometries -as in $\mathrm{LaCuMg}_{4}$ with $Z=3$ : $\mathrm{La}{ }_{3} \mathrm{Cu} 1{ }_{1} \mathrm{Cu} 2{ }_{2} \mathrm{Mg} 1{ }_{2} \mathrm{Mg} 2{ }_{1} \mathrm{Mg} 31_{1}$ - one atom of each kind is considered in the plots for the sake of establishing comparisons.

a- LaCu and LaCuMg. Looking firstly at the bonding within $\mathrm{LaCu}$, Fig. 4 a shows that within the valence band the $\mathrm{La}-\mathrm{Cu}$ interaction between atoms with respectively empty and filled valence states is bonding throughout the VB with positive COOP magnitudes. Two main bonding regions are observed: at $-4 \mathrm{eV}$ and in the neighborhood of EF. They correspond to the DOS positions of $\mathrm{Cu}-d$ and the itinerant part of La mainly constituted of La- $d$. The same feature is reproduced in panel b) relative to the COOP within $\mathrm{LaCuMg}$ characterized by bonding COOP throughout the VB albeit with a small anti-bonding contribution at the top of $\mathrm{Cu}-d$. The plots are more complex due to the presence of several interactions: $\mathrm{La}-\mathrm{Cu} 1$ and $\mathrm{La}-\mathrm{Cu} 2$ are dominating with respect to $\mathrm{Cu} 1-\mathrm{Mg}$ and $\mathrm{Cu} 2-\mathrm{Mg}(\mathrm{Mg} 3$ in Table 1). Note that in spite of the large $\mathrm{La}-\mathrm{Mg}$ separation $(\sim 3.15 \AA)$ there is a non-negligible $\mathrm{La}-\mathrm{Mg}$ bonding in the neighborhood of $\mathrm{E}_{\mathrm{F}}$ involving La- $d$ states and $\mathrm{Mg} s, p$. The overall bonding in $\mathrm{LaCuMg}$ is more differentiated and qualitatively larger than in the intermetallic. This further illustrates the origin of the larger cohesive energy (Table 1).

b- $\mathrm{LaCuMg}_{4}$. Due to the presence of several Mg substructures in the 1:1:4 compound, Fig. 5 details the different COOP in four panels. The La-Cu COOP shows a negligibly small magnitude $\mathrm{La}-\mathrm{Cu} 1$ bond whereas the whole $\mathrm{La}-\mathrm{Cu}$ bonding is ensured by $\mathrm{La}-$ $\mathrm{Cu} 2$. This follows from the different distances: $\mathrm{d}(\mathrm{La}-\mathrm{Cu} 1)=4.2 \AA$ while $\mathrm{d}(\mathrm{La}-\mathrm{Cu} 2)=$ $3.15 \AA$ A. Likewise $\mathrm{Cu} 1-\mathrm{Mg} 1$ bonding is negligibly small due to the large $\mathrm{Cu} 1-\mathrm{Mg} 1$ 
distance of 4.86 comparatively with $\mathrm{Cu} 1-\mathrm{Mg} 2$ 2.62 A and $\mathrm{Cu} 1-\mathrm{Mg} 3$ 2.86. Opposite features are observed for $\mathrm{Cu} 2-\mathrm{Mg} 1(\sim 2.9 \AA)$ which is dominating over the other two bonds. The fourth panel 5d) indicates dominant $\mathrm{La}-\mathrm{Mg} 3$ bonding with $\mathrm{d}(\mathrm{La}-\mathrm{Mg} 3)=$ $3.34 \AA$ while $\mathrm{d}(\mathrm{La}-\mathrm{Mg} 1)=3.56 \AA$ and $\mathrm{d}(\mathrm{La}-\mathrm{Mg} 2)=3.54 \AA$.

\section{Conclusions}

In this work we have reported original results of major effects brought by increasing amounts of magnesium to the electronic structure and hardness of $\mathrm{La}-\mathrm{Cu}-\mathrm{Mg}$ phases. Enhanced cohesive energies with respect to $\mathrm{LaCu}$ are identified, significant of improved stability due to $\mathrm{Mg}$ : While in $\mathrm{LaCu}$ binary the bonding is ensured by $\mathrm{La}-\mathrm{Cu}$ interaction, in the ternary compounds $\mathrm{La}-\mathrm{Cu}, \mathrm{La}-\mathrm{Mg}$, and $\mathrm{Cu}-\mathrm{Mg}$ contribute to the bonding and all electrons brought by $\mathrm{Mg}$ are located in bonding states thus providing enhanced cohesion to the crystal lattice. Compressibility increases along with the volume from $\mathrm{LaCu}$ to $\mathrm{LaCuMg}$ and $\mathrm{LaCuMg}_{4}$. However its change of $\Delta \mathrm{B}_{0} \sim 5 \mathrm{GPa}$ is not large enough to assign the only role to volume increase and a hindering role is assigned to the chemical bonding. Charge transfers are within the range of metallic behavior best highlighted in the $\mathrm{Mg}$ rich $\mathrm{LaCuMg}_{4}$ compound.

\section{Acknowledgements}

S.F.M. acknowledges financial support from French-Lebanese CEDRE PHC project (mission at USEK in July 2014). We are grateful for support from Conseil Régional d'Aquitaine as well as CSR-USEK and CNRS-L. Computational facilities were partly provided by MCIAUniversity of Bordeaux. 


\section{References}

[1] U. Ch. Rodewald, B. Chevalier, R. Pöttgen. J. Solid State Chem. 1801720 (2007).

[2] S. Linsinger, R. Pöttgen, Z. Naturforsch., 66b 565 (2011).

[3] D. Egusa, E. Abe, Acta Mater. 60, 166 (2012).

[4] S. Couillaud, E. Gaudin, J. L. Bobet, Intermetallics, 19336 (2011).

[5] S. Couillaud, E. Gaudin, J. Andrieux, S. Gorsse, M. Gayot, J.L. Bobet, Int. J. Hydrogen Energy, 3711824 (2012).

[6] S. De Negri, M. Giovannini, A. Saccone, J. Alloys Compounds 427134 (2007).

[7] P. Solokha, S. De Negri, V. Pavlyuka, A. Saccone, B.J. Marciniak, J. Solid State Chem., 1803066 (2007).

[8] S.F. Matar, B. Chevalier, R. Pöttgen. Intermetallics 3188 (2012).

[9] P. Hohenberg, W. Kohn, Phys. Rev. B, 136864 (1964).

[10] W. Kohn, L.J. Sham, Phys. Rev. A, 1401133 (1965).

[11] G. Kresse, J. Furthmüller, Phys. Rev. B 5411169 (1996).

[12] G. Kresse, J. Joubert, Phys. Rev. B 59, 1758 (1999).

[13] P. E. Blöchl, Phys. Rev. B 5017953 (1994).

[14] J. Perdew, K. Burke, M. Ernzerhof, Phys. Rev. Lett. 773865 (1996).

[15] H.J. Monkhorst, J.D. Pack, Phys. Rev. B, 135188 (1976).

[16] R. Bader. Chem. Rev. 91893 (1991).

[17] A.R. Williams, J. Kübler, C.D. Gelatt Jr., Phys. Rev. B 196094 (1979).

[18] V. Eyert, Int. J. Quantum Chem., 771007 (2000).

[19] V. Eyert, The Augmented Spherical Wave Method, Lect. Notes Phys. 849 (Springer, Berlin (2013).

[20] Z. Wu, R. E. Cohen, Phys. Rev. B 73235116 (2006).

[21] P. E. Blöchl, Phys. Rev. B 4916223 (1994).

[22] R. Hoffmann, Angew. Chem. Int. Ed. Engl., 26, 846 (1987).

[23] S. Cirafici, A. Palenzona, J. Less Comm. Met. 53199 (1977). 
[24] F. Birch, J. Geophys. Res. 831257 (1978).

[25] S.F. Matar Solid State Sci., 1259 (2010). 
Table 1 Experimental and calculated crystal data for the isostructural hexagonal $\mathrm{LaCuMg}_{4}$ and $\mathrm{LaCuMg}$ ternary compounds and for $\mathrm{LaCu}$ binary in FeB structure.

a) $\mathrm{LaCuMg}_{4}$

\begin{tabular}{|c|c|c|c|}
\hline $\begin{array}{l}\mathrm{LaCuMg}_{4} \quad P \overline{6} m 2, \\
Z==3 \mathrm{FU}\end{array}$ & Experimental [7] & Calc. (this work) & $\begin{array}{l}\text { Calculated Bader } \\
\text { charges (Qle) }\end{array}$ \\
\hline$a / \AA$ & 10.3911 & 10.322 & \\
\hline$c / \AA$ & 4.5126 & 4.521 & \\
\hline $\mathrm{V} / \AA^{3}$ & 421.98 & 417.50 & \\
\hline $\mathrm{La}(3 f)$ & $0.4064,0,0$ & $0.407,0,0$ & +0.58 \\
\hline $\mathrm{Cu} 1(1 a)$ & $0,0,0$ & $0,0,0$ & -0.81 \\
\hline $\mathrm{Cu} 2(2 c)$ & $1 / 3,2 / 3,0$ & $1 / 3,2 / 3,0$ & -0.70 \\
\hline $\operatorname{Mg} 1(6 k)$ & $0.2935,0.4746,1 / 2$ & $0.297,0.480,1 / 2$ & 0 \\
\hline $\operatorname{Mg} 2(3 f)$ & $0.7475,0,0$ & $0.746,0,0$ & +0.03 \\
\hline $\operatorname{Mg} 3(3 g)$ & $0.1696,0,1 / 2$ & $0.166,0,1 / 2$ & +0.08 \\
\hline $\begin{array}{l}\mathrm{d}(\mathrm{Cu} 1-\mathrm{Mg} 1) \\
\mathrm{d}(\mathrm{Cu} 1-\mathrm{Mg} 2) \\
\mathrm{d}(\mathrm{Cu} 2-\mathrm{Mg} 1) \\
\mathrm{d}(\mathrm{Cu} 2-\mathrm{La})\end{array}$ & $\begin{array}{l}2.62 \\
2.86 \\
2.90 \\
3.15\end{array}$ & $\begin{array}{l}2.62 \\
2.84 \\
2.87 \\
3.13\end{array}$ & \\
\hline Energy $(\mathrm{eV}) / 3 \mathrm{FU}$ & & -46.87 & $E_{\text {coh. }}=-1.41 \mathrm{eV} / \mathrm{FU}$ \\
\hline
\end{tabular}

b) $\mathrm{LaCuMg}$

\begin{tabular}{|l|l|l|l|}
\hline $\begin{array}{l}\text { LaCuMg } P \overline{6} m 2, Z= \\
3 \mathrm{FU}\end{array}$ & Experimental [6] & Calc. (this work) & $\begin{array}{l}\text { Calculated Bader } \\
\text { charges (Qle) }\end{array}$ \\
\hline$a / \AA$ & 7.725 & 7.597 & \\
\hline$c / \AA$ & 4.188 & 4.201 & \\
\hline $\mathrm{V} / \AA^{3}$ & 216.44 & 210.2 & \\
\hline $\mathrm{La}(3 f)$ & $0.582,0,0$ & $0.407,0,0$ & +0.63 \\
\hline $\mathrm{Cu} 1(1 a)$ & $0,0,0$ & $0,0,0$ & -0.94 \\
\hline $\mathrm{Cu} 2(2 c)$ & $1 / 3,2 / 3,1 / 2$ & $1 / 3,2 / 3,1 / 2$ & -0.77 \\
\hline $\mathrm{Mg} 3(3 g)$ & $0.256,0,1 / 2$ & $0.166,0,1 / 2$ & +0.18 \\
\hline $\mathrm{d}(\mathrm{Cu} 1-\mathrm{Mg} 3)$ & 2.79 & 2.76 & \\
$\mathrm{~d}(\mathrm{Cu} 2-\mathrm{La})$ & 3.12 & 3.10 & \\
\hline Energy $(\mathrm{eV}) / 3 \mathrm{FU}$ & & -32.11 & $E_{\text {coh. }}=-0.67 \mathrm{eV} / \mathrm{FU}$ \\
\hline
\end{tabular}

c) $\mathrm{LaCu}$

\begin{tabular}{|l|l|l|l|}
\hline $\begin{array}{l}\mathrm{LaCu} \\
Z=4 \mathrm{FU}\end{array}$ & Enma & Experimental [23] & $\begin{array}{l}\text { Calculated (this work) } \\
\text { charges (Qle) }\end{array}$ \\
\hline$a / \AA$ & 7.543 & 7.503 & \\
\hline$b / \AA$ & 4.616 & 4.562 & \\
\hline$c / \AA$ & 5.724 & 5.661 & \\
\hline $\mathrm{V} / \AA^{3}$ & 199.30 & 195.39 & \\
\hline $\mathrm{La}(4 c)$ & $0.179,1 / 4,0.135$ & $0.177,1 / 4,0.134$ & +0.97 \\
\hline $\mathrm{Cu}(4 c)$ & $0.035,1 / 4,0.626$ & $0.035,1 / 4,0.608$ & -0.97 \\
\hline $\mathrm{d}(\mathrm{La}-\mathrm{Cu})$ & 3.01 & 3.0 & \\
\hline Energy $(\mathrm{eV}) / 4 \mathrm{FU}$ & & -35.98 & $E_{\text {coh. }}=-0.35 \mathrm{eV} / \mathrm{FU}$ \\
\hline
\end{tabular}




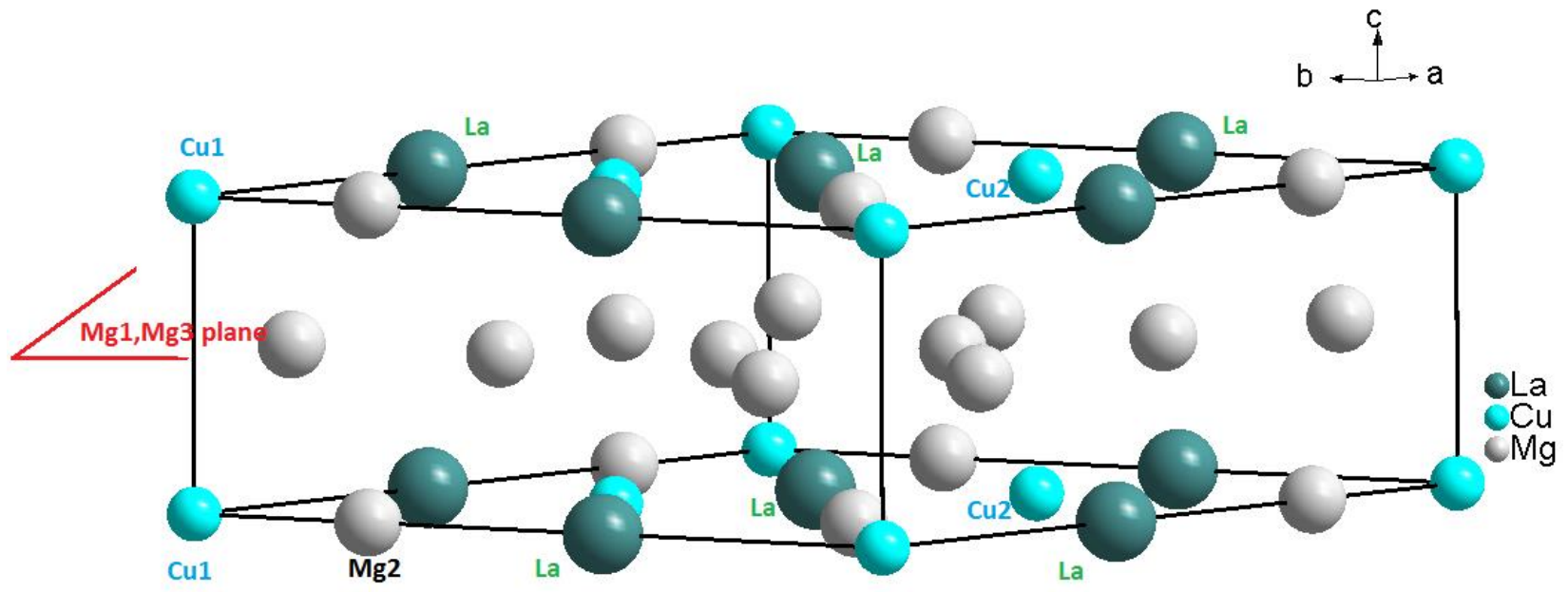

a)

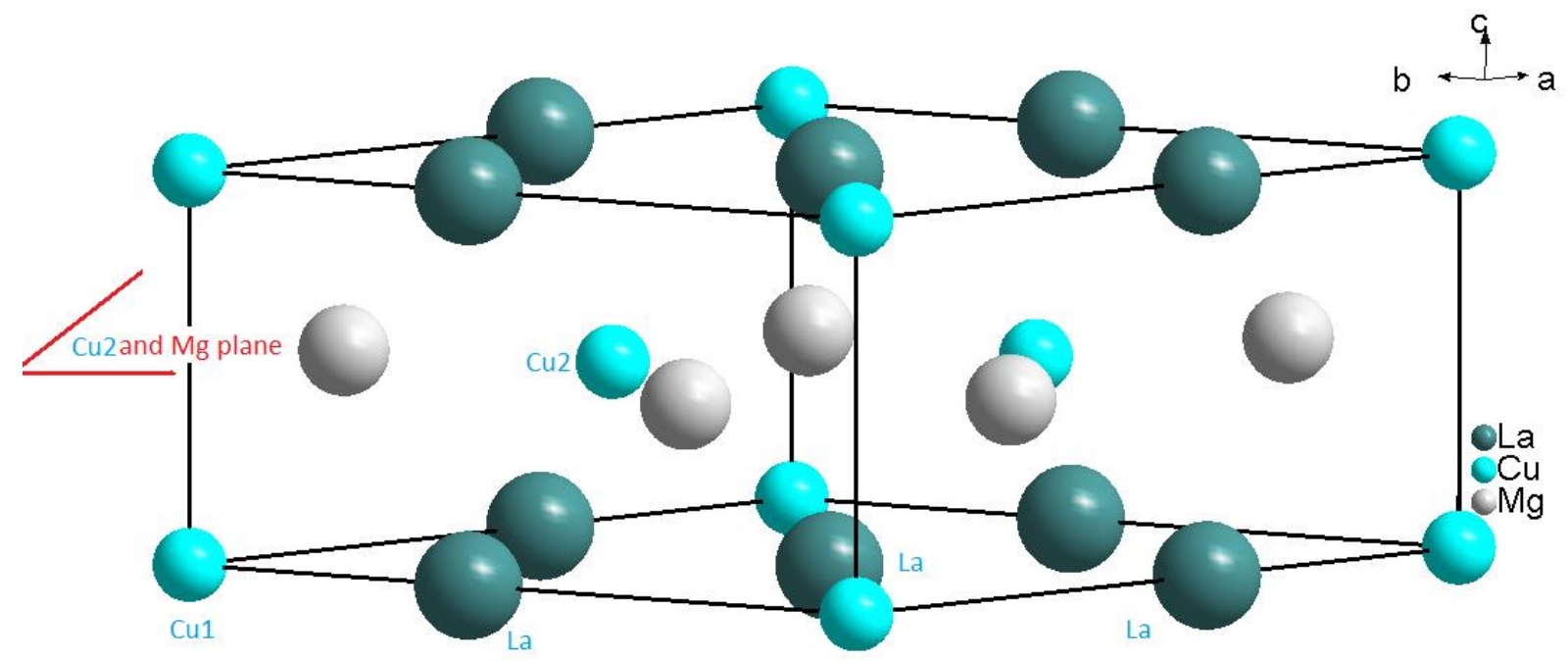

b)

Fig.1. Sketches of the crystal structures of $\mathrm{LaCuMg}_{4}$ (a) and $\mathrm{LaCuMg}$ (b) 

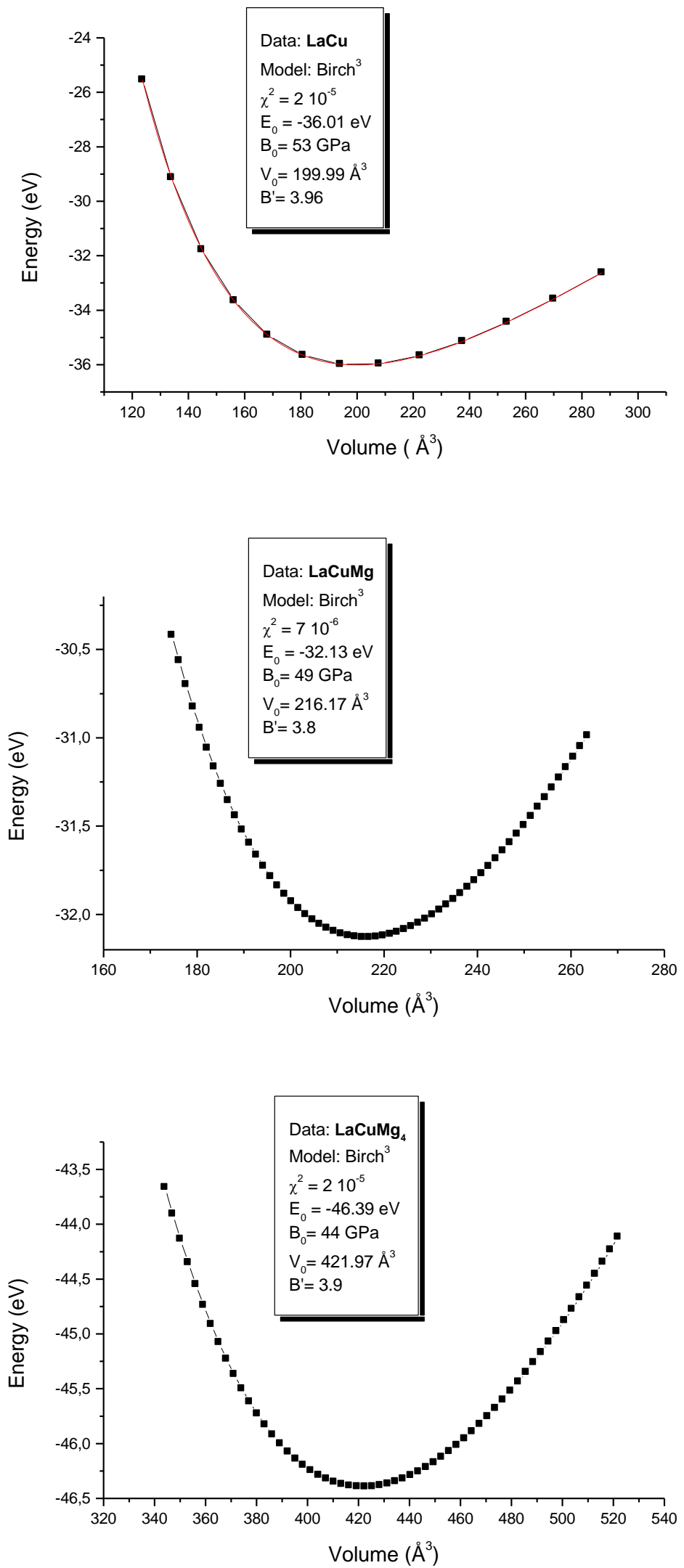

Fig.2. Energy volume curves and Birch EOS fit parameters (inserts) of $\mathrm{LaCu}$ (a), $\mathrm{LaCuMg}$ (b) and $\mathrm{LaCuMg}_{4}$ (c). 


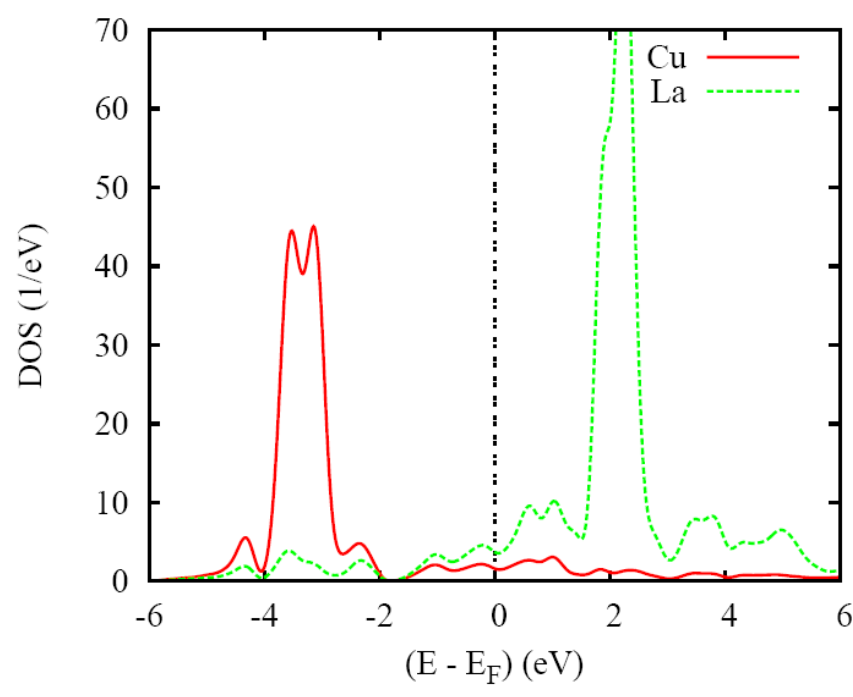

(a)

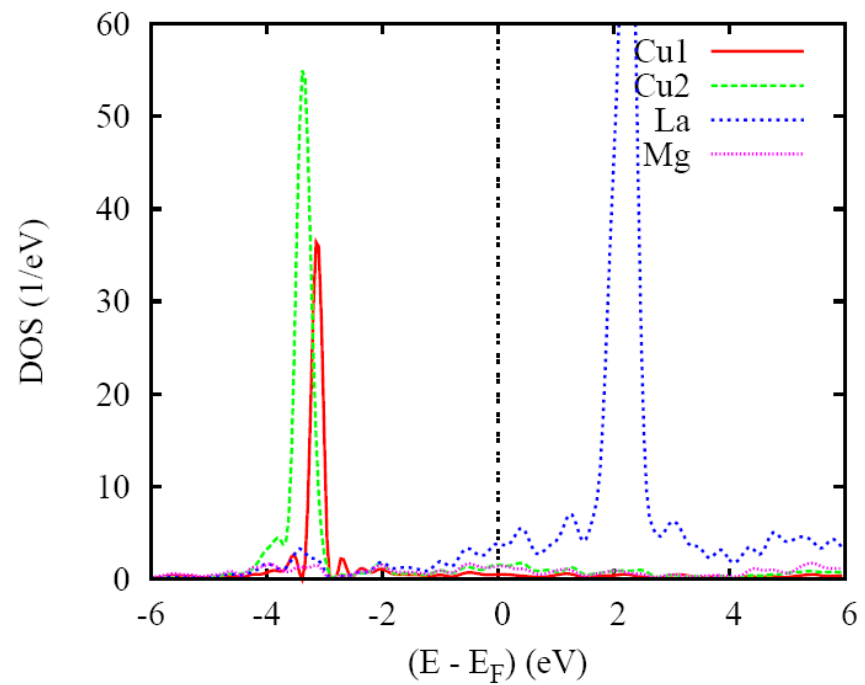

(b)

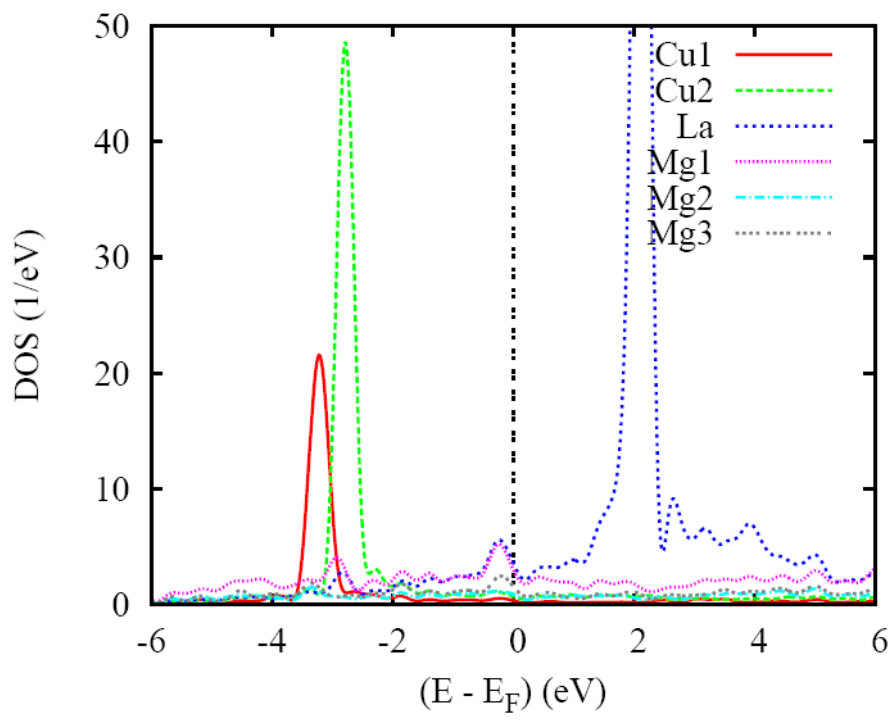

(c)

Fig.3. Site projected DOS for $\mathrm{LaCu}(\mathrm{a}), \mathrm{LaCuMg}$ (b) and $\mathrm{LaCuMg}_{4}$ (c). 

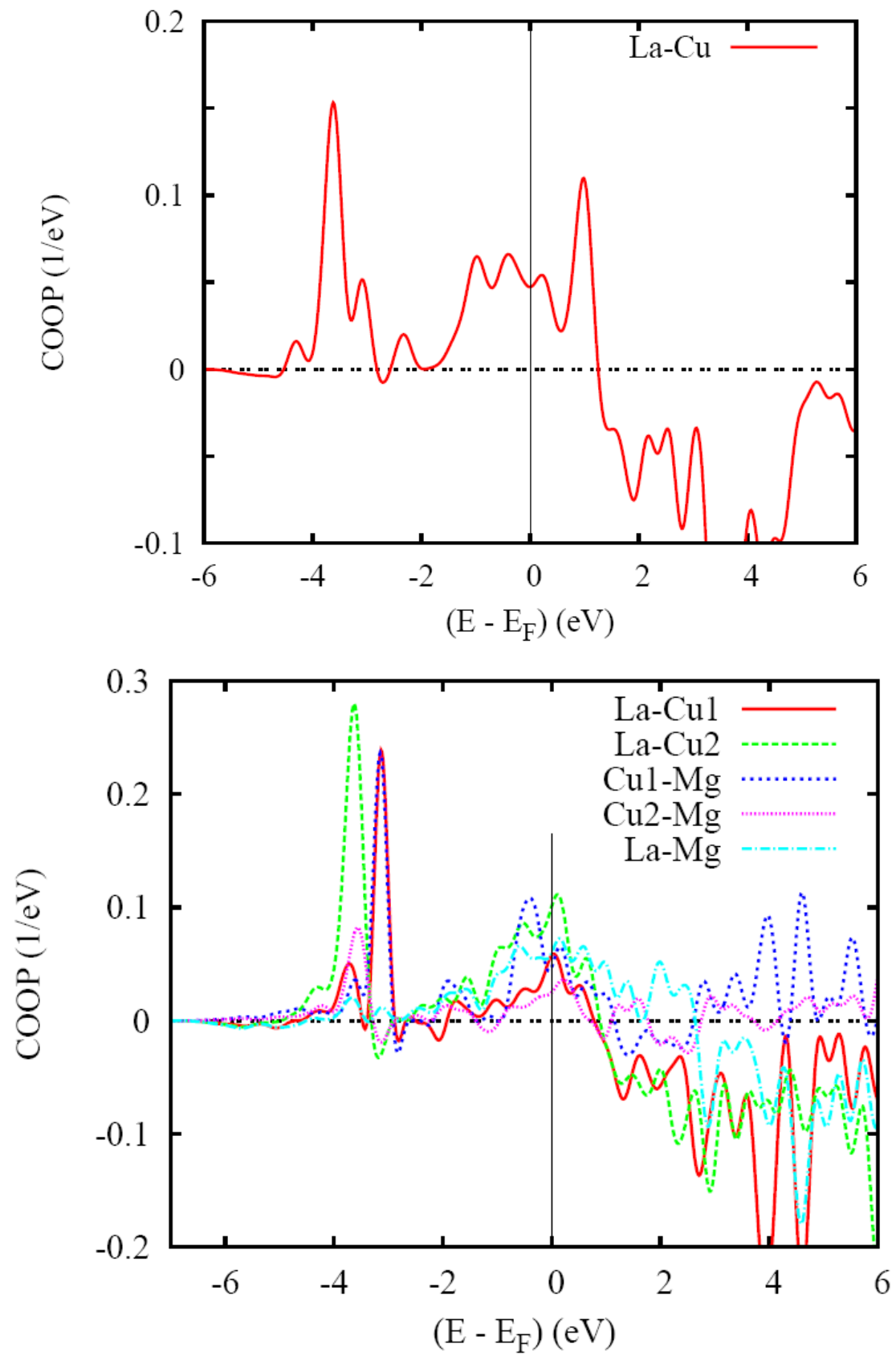

Fig.4. COOP of $\mathrm{LaCu}$ and $\mathrm{LaCuMg}$ 

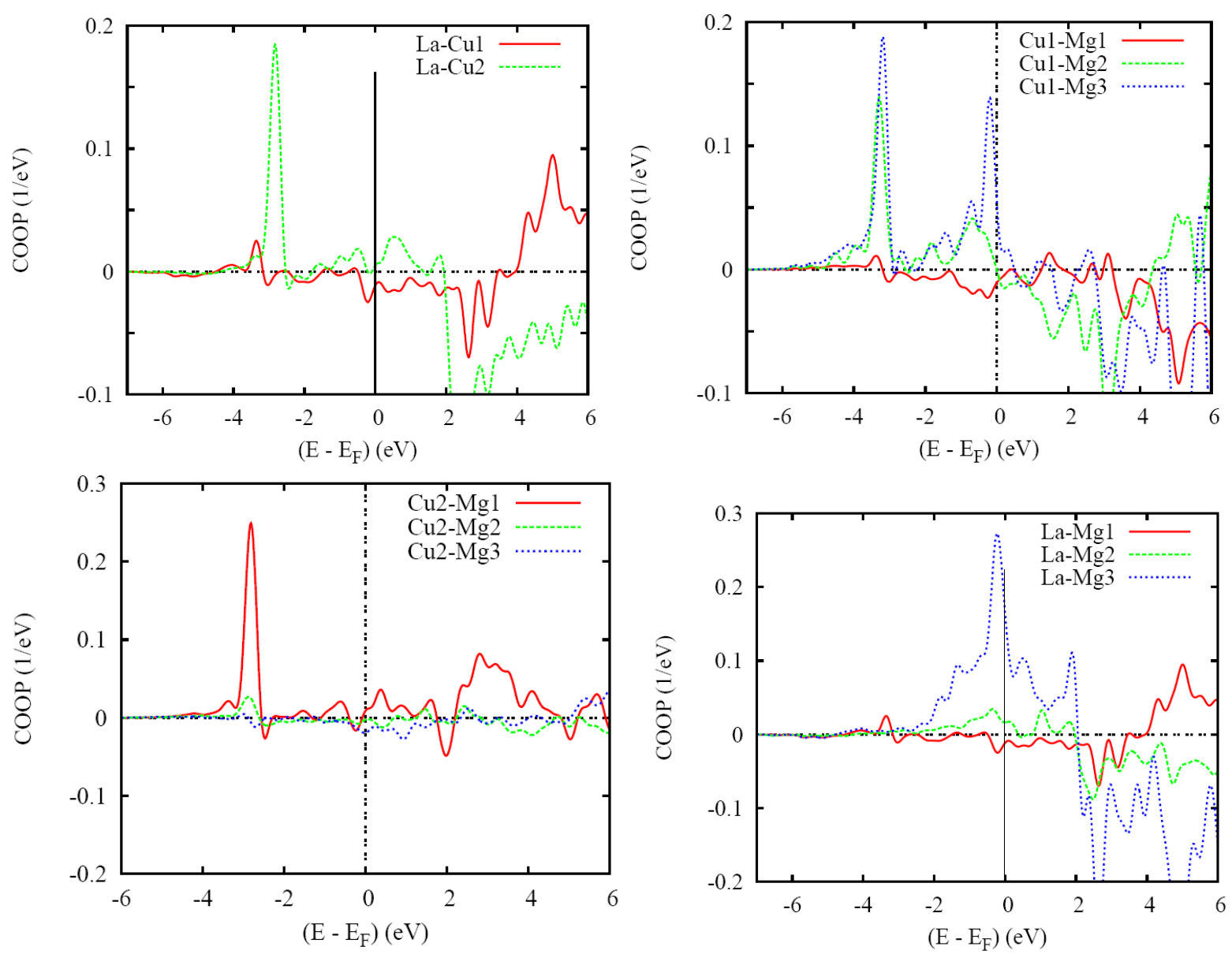

Fig.5. COOP of the different atom-to-atom interactions in $\mathrm{LaCuMg}_{4}$ 